\title{
Investigation on Seismic Behavior of CFRP Retrofitted Reinforced Concrete Column with Partial Deterioration: Experimental and Numerical
}

\author{
Z. M. Wu, D. X. Hou, and W. Dong
}

\begin{abstract}
Due to frost damage or insufficient vibration during construction, partial deterioration of reinforced concrete (RC) columns commonly exist in practical engineering, which would weaken the seismic behaviors of the structure. The work of strength is needed for the RC columns with deterioration. Thus, in this paper, the seismic behavior of CFRP retrofitted reinforced concrete column with partial deterioration was investigated by numerical and experimental approaches. Firstly, a numerical model was proposed to analyze seismic behavior of partially deteriorated RC columns and CFRP retrofitting columns. Then, the experiment with six specimens was carried out to validate the numerical results. It is found that the proposed numerical model can be used to analysis the seismic behaviors of CFRP retrofitted reinforced concrete column with partial deterioration.
\end{abstract}

Index Terms-Numerical analysis, partially deteriorated, CFRP, seismic behavior

\section{INTRODUCTION}

Many factors such as freezing, and insufficient vibration during construction may deteriorate the strength of concrete. In most cases, partial deterioration is more common in practical engineering, which might weaken the seismic behaviors of the whole columns. Thus, it is necessary to strengthen these partially deteriorated RC columns. Carbon Fiber Reinforced Polymers (CFRP) sheets is widely used to retrofit RC columns in practice

Many researchers have examined the seismic behaviors of RC columns retrofitted with CFRP. For example, Colomb et al. studied the seismic behaviors of RC short columns retrofitted with CFRP sheets [1]. The research indicated that the seismic behaviors of $\mathrm{RC}$ columns are improved significantly. Ye et al. also studied the seismic behaviors of short column with CFRP, and proposed a method to calculate the amount of required CFRP sheets [2] . Rechart et al., vstudied the seismic behaviors of CFRP retrofitted RC long columns with circular sections [3]. The results showed that the retrofitting function of CFRP is related to the axial load of column, the amount of CFRP, and the inner reinforcements.

However, most available literatures mainly focused on CFRP retrofitting RC columns with intact strength, few

Manuscript received May 15, 2013; revised July 5, 2013. This work was supported by the National Natural Science Foundation of China under the grant NSFC51121005.

The authors are with the State Key Laboratory of Coastal and Offshore Engineering, Dalian University of Technology, Dalian 116024, China (e-mail: Zhiminwu2002@yahoo.com.cn, dongxv666@126.com, dongwei@dlut.edu.cn). researches focused on the partially deteriorated RC columns. Wei et al. examined the axial and eccentric compressive behaviors of CFRP retrofitting partially deteriorated RC columns [4]-[6]. Nevertheless, Wei et al., has not investigated the seismic behaviors of CFRP retrofit partially deteriorated columns.

The objective of this paper is to investigate the seismic performances of flexure-dominant partially deteriorated RC columns and try to retrofit the partially deteriorated columns with CFRP. The finite element analysis of the seismic behaviors of partially deteriorated RC columns and CFRP retrofitting specimens was carried out using software ABAQUS. The validity of finite element model was then verified by the results from laboratory tests of six specimens. There is a good agreement between experimental and numerical results.

\section{Finite ElEMENT ANALysis}

\section{A. Modeling of Specimens}

Finite element analysis was conducted with software ABAQUS [7]. The simulated specimens include six columns with different intact strength $f_{\text {in }}$ and deteriorated strength $f_{w}$, retrofitted with different thickness CFRP $t_{c f f p}$. The specimens have the same height $L$, diameter $D$, and axial load ratio $N /\left(f_{i n} A\right)$. All the deteriorated range $R$ of columns was spread from the foot of the columns up to the height of $250 \mathrm{~mm}$ above the foot of the columns. The details of the numerical models were shown in Table I and Fig. 1.
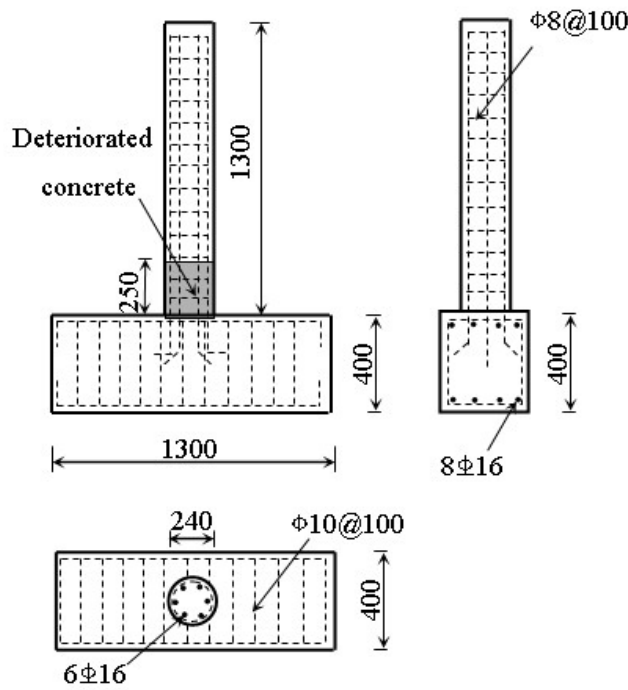

Fig. 1. Notation of geometrical parameters of specimens 
TABLE I: GeOMETRICAL AND MATERIAL PARAMETERS OF PECIMENS

\begin{tabular}{|c|c|c|c|c|c|c|c|}
\hline Specimen & $\begin{array}{c}D \\
(\mathrm{~mm})\end{array}$ & $\begin{array}{c}L \\
(\mathrm{~mm})\end{array}$ & $\begin{array}{c}R \\
(\mathrm{~mm})\end{array}$ & $\begin{array}{c}f_{\text {in }} \\
(\mathrm{MPa})\end{array}$ & $\begin{array}{c}f_{w} \\
(\mathrm{MPa})\end{array}$ & $N /\left(f_{i n} A\right)$ & $\begin{array}{c}t_{c f r p} \\
(\mathrm{~mm})\end{array}$ \\
\hline DB50 & 240 & 1300 & - & 52 & - & 0.1 & - \\
\hline BR200 & 240 & 1300 & $0-250$ & 52 & 22 & 0.1 & 0 \\
\hline BR300 & 240 & 1300 & $0-250$ & 52 & 31 & 0.1 & 0 \\
\hline BR301 & 240 & 1300 & $0-250$ & 52 & 31 & 0.1 & 0.167 \\
\hline BR302 & 240 & 1300 & $0-250$ & 52 & 31 & 0.1 & 0.334 \\
\hline BR203 & 240 & 1300 & $0-250$ & 52 & 22 & 0.1 & 0.501 \\
\hline
\end{tabular}

\section{A. Boundary Conditions and Load Application}

The stub of column was restrained against all degrees of freedom. The displacement of stub in the $\mathrm{x}$-axis direction was also restrained during loading. The top and lateral loading plates were tied on the top of columns to prevent local crashing of concrete. Firstly, the axial compressive load was applied on the loading plate. Then the laterally circular load was applied on the lateral loading plate. The reinforced bars were embedded into the concrete, and the slippage between them was neglected. The boundary conditions and load application of specimen was shown in Fig. 2.

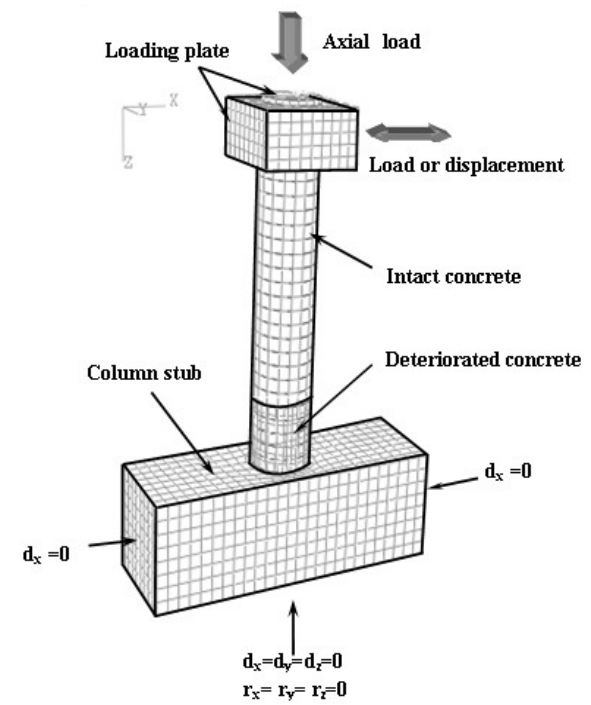

Fig. 2. FE model of specimen

\section{B. Element Type and Mesh}

An eight nodes 3-D solid element (C3D8R) was used to model concrete. The longitudinal and transverse steel bars were simulated by truss element (T3D2). The structured meshing technique was used for meshing. The maximum dimension of aggregate was $20 \mathrm{~mm}$, thus $50 \mathrm{~mm}$ and $35 \mathrm{~mm}$ were selected as the size of concrete and reinforcement grid, respectively.

\section{Modeling of Material Properties}

The damaged plasticity concrete model defined in Standard ABAQUS is used in the analysis. The yield function was developed by Lublinear [8], and modified by Jeeho [9]. The unaxial stress-strain relationship of compressive and tension behaviors are required. Attard [10] model was adopted as the compressive constitutive law of concrete in this study as shown in Fig. 3. The model of Mark [11] was selected as the compressive damage model; the damage was presented by means of damage ratio variation during transverse loading, as shown in Fig. 4. The tension strength of concrete $f_{t}$ is equal to $0.3 f_{c}{ }^{2 / 3}$ according to the CEO-FIB2010 [12]. Shah's model [13] was used as tensile behavior of concrete. The tension behavior was shown in Fig. 5.

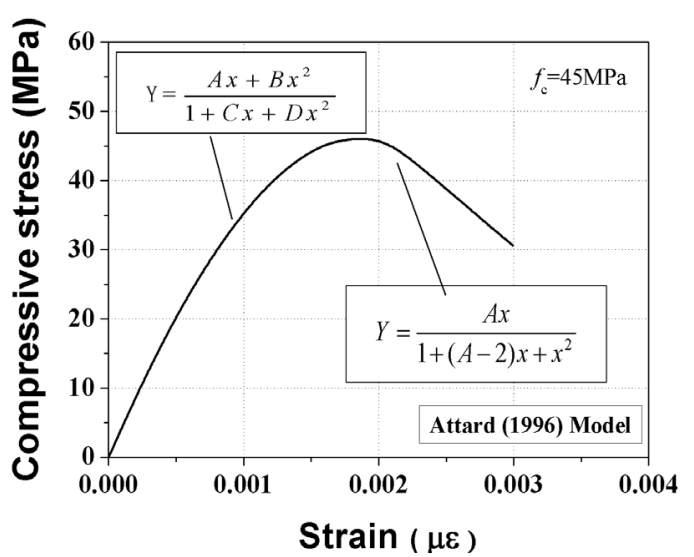

Fig. 3. Compressive model of concrete

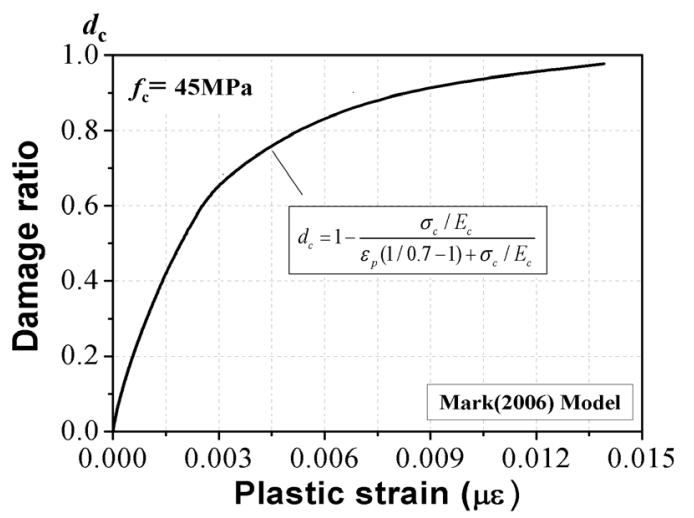

Fig. 4. Compressive damage model of concrete

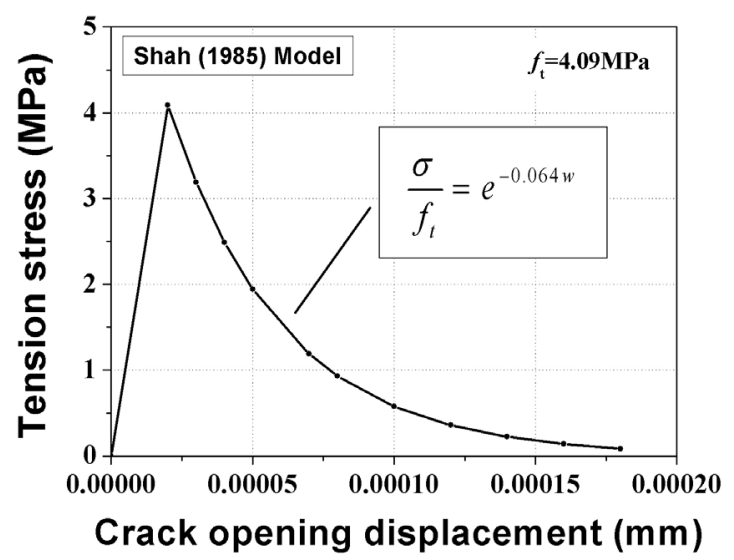

Fig. 5. Tension model of concrete

The steel bar was assumed as a hardening elastic-plastic material. The stress-strain curve used in the numerical analysis is shown in Fig.6. The yield strength of deformed steel bar and plain bar is $360 \mathrm{MPa}$ and $290 \mathrm{MPa}$, respectively, 
the ultimate strength of which is $580 \mathrm{MPa}$ and $420 \mathrm{MPa}$, and the elastic modulus of which is $206 \mathrm{GPa}$ and $210 \mathrm{GPa}$. The hardening modulus was considered as one percent of the elastic modulus.

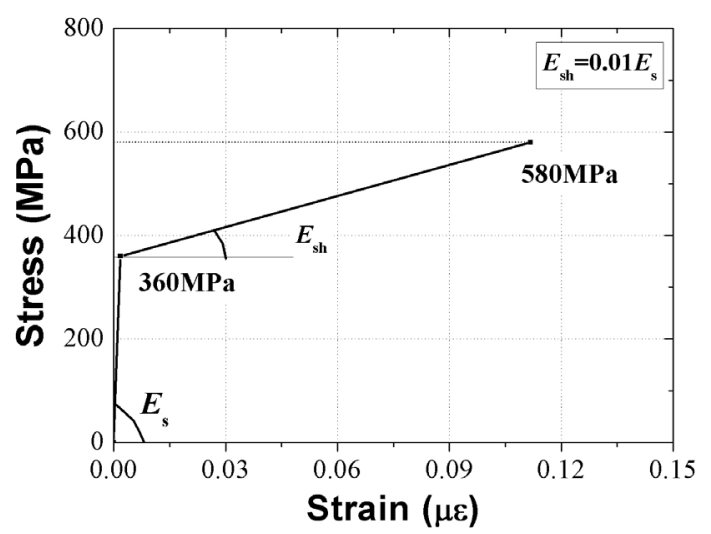

Fig. 6. Hardening elastic-plastic of steel bar

CFRP sheets were defined as an orthotropic elastic lamina in ABAQUS. The following parameters were required in finite element analysis: The elastic modulus in tensile direction $E_{c f r p}$, Poisson's ratio $v_{c f r p}$ and ultimate stress $f_{c f r p}$ were $235 \mathrm{GPa}, 0.25$ and $3400 \mathrm{MPa}$, respectively, all of which were obtained from coupon test. Reduced integration quadrilateral membrane element with four nodes (M3D4R) was used to define CFRP. The slippage between CFRP and concrete was ignored, and the CFRP material was tie to the concrete.

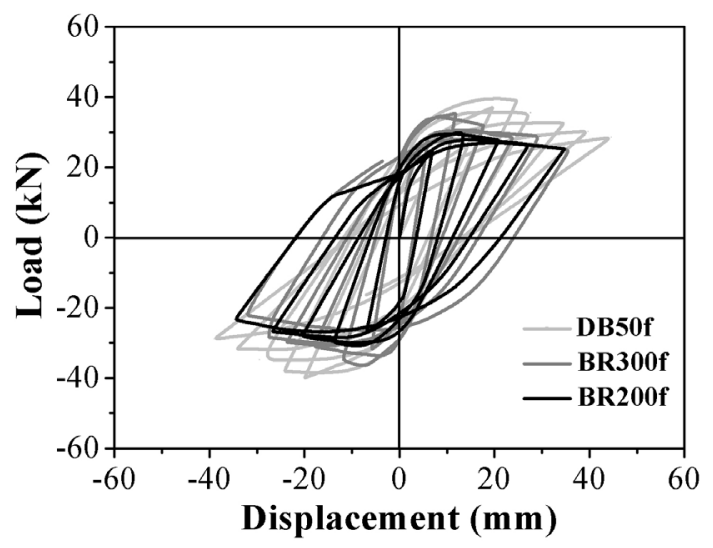

Fig. 7. Predicted hysteretic loops of deteriorated and control column

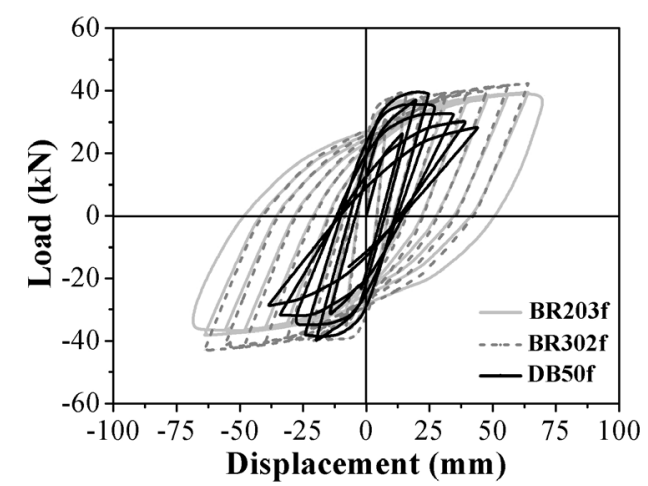

Fig. 8. Predicted hysteretic loops of retrofitted and control column

\section{Numerical Results}

The numerical results showed in Fig. 7, which indicated that when the deteriorated segment locates at the foot of the column, the seismic behaviors of RC columns are weakened seriously. The influence of the deteriorated segment on the seismic behaviors is related to the deteriorated strength. The retrofitting effect of wrapped CFRP was shown in Fig. 8, which indicated that the bearing capacity of deteriorated column with deteriorated strength $22 \mathrm{MPa}$ can almost reach to the one of the control column after retrofitting 3 layers CFRP, and the deteriorated column with deteriorated strength $31 \mathrm{MPa}$ requires 2 layers CFRP.

\section{EXPERIMENTAL VERIFICATIONS}

The FE model described above has been validated against the test results carried out in the laboratory. A total of six flexure-dominant specimens, including two partially deteriorated columns, three retrofitted deteriorated columns and one reference column, were tested. The details of test specimens are corresponding to the numerically simulated specimens, which were shown in Table I.

\section{A. Experiment}

The experimental instruments were shown in Fig. 9. Each column was placed in an existing frame with a 200t hydraulic actuator. The column stubs were fastened to the rigid floor with four high-strength rods to prevent slip and overturning under large lateral loads. The actuator with a $200 \mathrm{t}$ load cell was mounted vertically onto the frame to apply the vertical axial load. Another two 30t horizontal hydraulic actuators with load cells were used to apply lateral reversal load. All instruments were connected to IMC data acquisition system for data selection. Before yield of the longitudinal bars, the horizontal load was applied in accordance to the load control mode, and the displacement control mode was adopted after yielding of longitudinal bar.

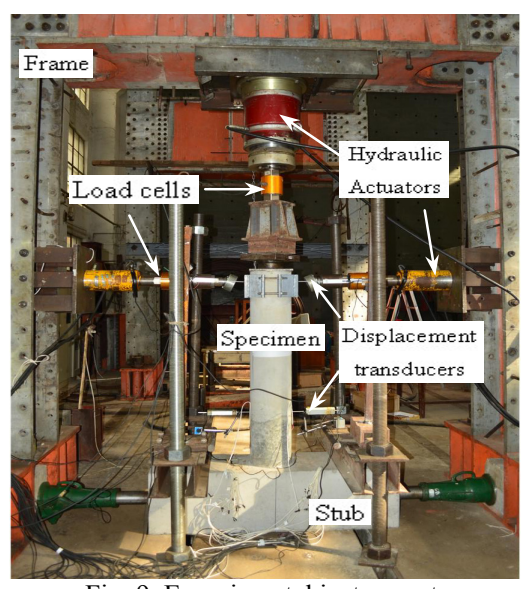

Fig. 9. Experimental instrument

\section{B. Verifications of Proposed FE Model}

The hysteretic loops were shown in Fig.10 (a)-(e). It is clearly visible that the experimental results have a good agreement with the FEA results. The bearing capacities of experimental and analytical results were shown in Table 2. Owing to the ignoring of slippage between concrete and reinforcement bars, the displacements of the partially deteriorated columns in FEM analysis are slight smaller than the test result. The experimentally hysteretic loops present the same regularity to the ones obtained from finite element analysis, which indicates the proposed FE model is valid to 
predict the seismic behaviors of partially deteriorated columns, and the effectiveness of externally wrapped CFRP on retrofitting partially deteriorated columns.

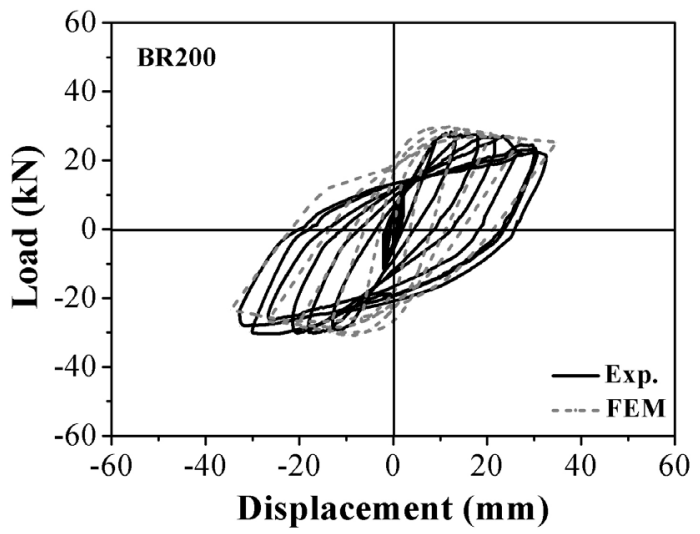

(a)

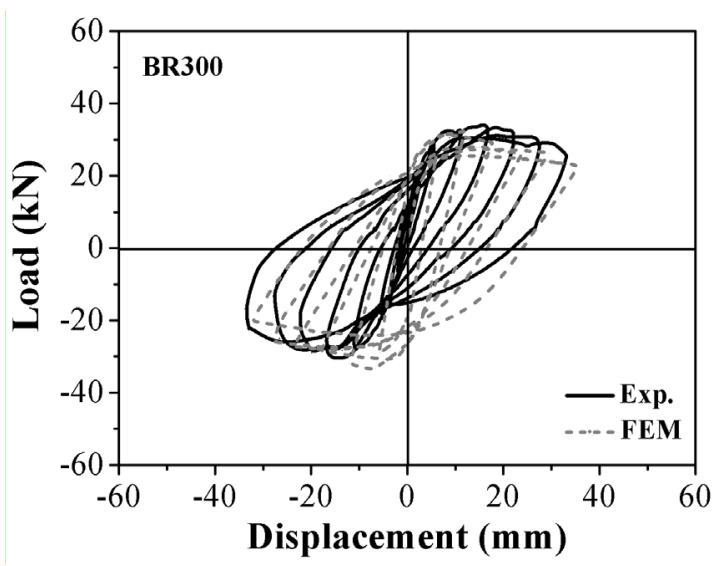

(b)

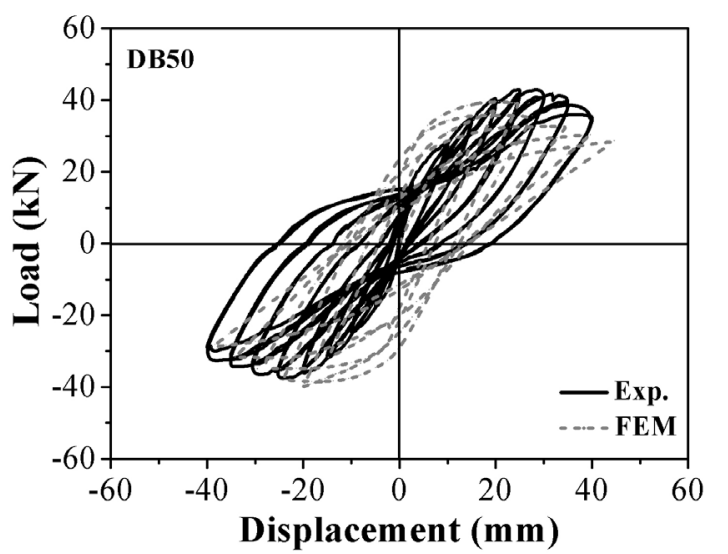

(c)

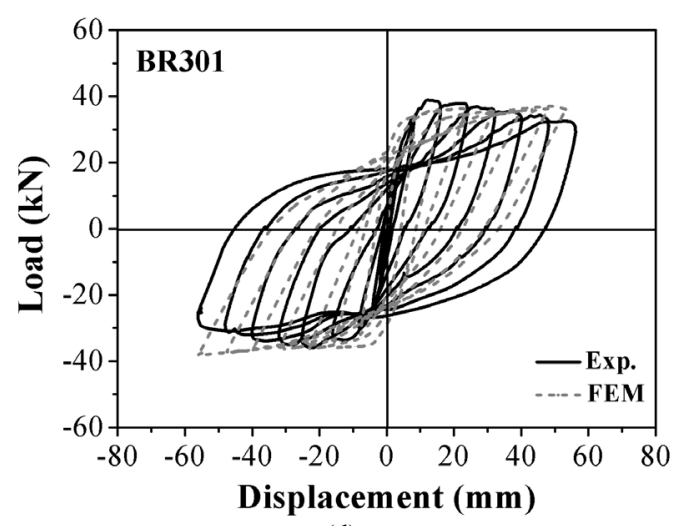

(d)

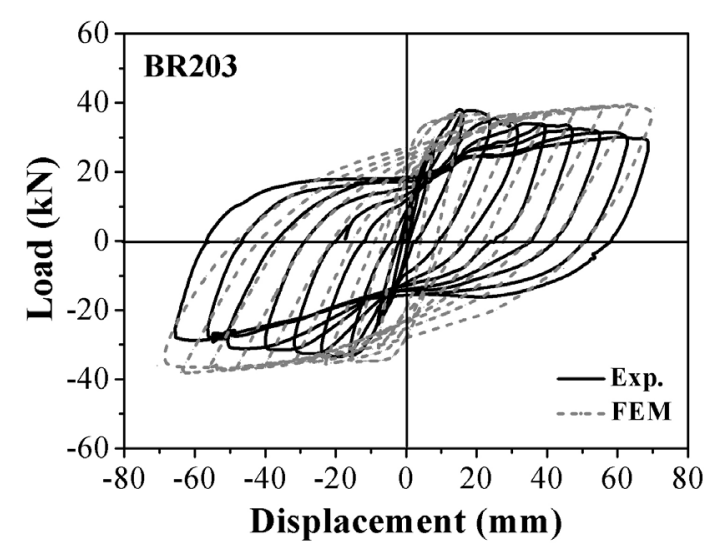

(e)

Fig. 10. Hysteretic loops of experimental and FEA results

\begin{tabular}{cccc}
\multicolumn{4}{c}{ TABLE II: TEST AND FEA RESULTS } \\
\hline Specimen & $N_{\text {exp }}$ & $N_{F E M}$ & $N_{\text {exp }}-N_{F E M} \mid \times 100 \%$ \\
\hline & $(\mathrm{kN})$ & $(\mathrm{kN})$ & $N_{\text {exp }}$ \\
\hline DB50 & 42.6 & 39.2 & $7.9 \%$ \\
BR200 & 29.8 & 30.1 & $10.0 \%$ \\
BR203 & 39.1 & 39.8 & $1.8 \%$ \\
BR300 & 35.6 & 34.4 & $3.4 \%$ \\
BR301 & 38.9 & 37.2 & $4.3 \%$ \\
BR302 & 41.0 & 41.6 & $1.5 \%$ \\
\hline \hline
\end{tabular}

\section{CONCLUSION}

According to the analytically and experimentally research results, the following conclusions are obtained:

1) 3-D finite element model can predict the seismic behaviors of partially deteriorated columns and the effect of externally wrapped CFRP.

2) When the deteriorated segment locates at the foot of the columns, the partial deterioration can weaken the seismic behaviors of the whole columns.

3) Wrapping CFRP is an effective method to recover the seismic behaviors of the partially deteriorated column.

\section{REFERENCES}

[1] F. Colomb, H. Tobbi, E. Ferrier, and P. Hamelin, "Seismic retrofit of reinforced concrete short columns by CFRP materials," Composite Structures, vol. 82, no. 4, pp. 475-487, 2008.

[2] L. Ye, K. Zhang, S. Zhao, and P. Feng, "Experimental study on seismic strengthening of RC columns with wrapped CFRP sheets," Construction and Building Materials, vol. 17, no. 6-7, pp. 499-506, 2003.

[3] D. Richart, A. Shamim, and B. Oguzhan, "Retrofit of square concrete columns with carbon fiber-reinforced polymer for seismic resistance," ACI Structural Journal, vol. 100, no. 6, pp. 785-794, 2003.

[4] H. Wei, Z. Wu, X. Guo, and F. Yi, "Experimental study on partial deteriorated strength concrete columns confined with CFRP," Engineering Structures, vol. 31, no. 10, pp. 2495-2505, 2009.

[5] H. Wei, Z. Wu, and P. Zhang, "Axial experiment on CFRP confined steel reinforced concrete columns with partial deteriorated strength," Journal of Reinforced Plastics and Composites, vol. 29, no. 6, pp. 874-882, 2010.

[6] H. Wei, "Compressive performance study on CFRP wrapped concrete columns with partial deteriorated strength," Ph.D. Dissertation. Dept. Civil Engineering, DUT, Dalian. China 2009.

[7] ABAQUS standard user's manual, Hibbitt, Karlsson and Sorensen, Inc., version 6.8-1, 2008.

[8] J. Lubliner, J. Oliver, S. Oller, and E. Onate, "A plastic-damage model for concrete," Journal of Solids and Structures, vol. 25, no. 3, pp. 299-326, 1989.

[9] J. Lee and L. Fenves, "Plastic-damage model for cyclic loading of concrete structures," Journal of Engineering Machanics, vol. 124, no. 8, pp. 892-902, 1998. 
[10] M. Attard and S. Setunge, "Stress-strain relationship of confined and unconfined concrete," ACI Material Journal, vol. 3, no. 5, pp. 432-441, 1996.

[11] P. Mark and V. Birtel, "Parameterised finite element modelling of RC beam shear failure," in Proc. of 2006 ABAQUS User's Conf., Bochum, 2006, pp. 95-108.

[12] CEB-FIB model code 2010.Bulletin55, International Federation for Structural Concrete, 2010.

[13] V. Gopalaratnam and S. Shah, "Softening response of plain concrete in direct tension," ACI Material Journal, pp. 310-323, May-June 1985.

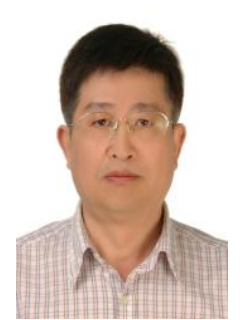

Z. M. Wu was born in Zhejiang Province, China, November, 1963. He received his bachelor degree in engineering (Combustion Engine) from Dalian University of Technology, Dalian, China in 1986. And he received his master degree in engineering (Experimental Mechanics) from Dalian University of Technology, Dalian, China in1989. Then he got his $\mathrm{Ph}$. $\mathrm{D}$ in civil engineering from the same university in 1993. His current research fields are concrete fracture mechanics and concrete reinforcement theory.

$\mathrm{He}$ is a professor at Department of Civil Engineering, Dalian University of Technology. Before that, he conducted post-doctoral research at Dalian University of Technology from 1993 to 1995 . He was a Visiting Scholar at Leipzig University of Applied Sciences, Germany from 2002 to 2003, and a Senior Visiting Scholar at City University of Hong Kong on 2007.

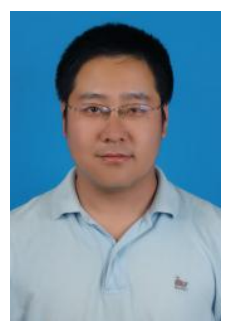

D. X. Hou was born in Liaoning Province, China, December, 1983. He received his bachelor degree in civil engineering from Shenyang University, Shenyang, China, in 2006. In 2009, he obtained his master degree in structural engineering, Shenyang Jianzhu University, Shenyang, China. He is pursuing his Ph.D degree in Dalian University of Technology, Dalian, China. His research field is concrete reinforcement theory.

$\mathrm{He}$ is a Ph.D student at the Department of Civil Engineering, Dalian University of Technology.

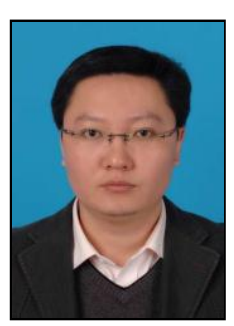

W. Dong was born in Liaoning Province, China, $6^{\text {th }}$ October, 1978. He received his bachelor degree in civil engineering from Dalian University of Technology, Dalian, China, in September 2001 He got his PhD. on Civil Engineering, from Dalian University of Technology, Dalian, China, April, 2008 His research field is concrete fracture mechanics.

$\mathrm{He}$ is a lecturer at Department of Civil Engineering, Dalian University of Technology. He joined Dalian University of Technology in April 2010. Before that, he conducted post-doctoral research at Dalian University of Technology from April 2008 to April 2010. He worked as a Research Fellow at School of Engineering and Design, Brunel University, UK from March 2012 to March 2013.

Dr. Dong a National First-class Registrations Structural Engineer of China. 